\title{
Práticas Educativas Maternas e Paternas aos 24 e aos 72 Meses de Vida da Criança ${ }^{1}$
}

\author{
Angela Helena Marin ${ }^{2}$ \\ Universidade Federal do Rio Grande do Sul \\ Universidade Luterana do Brasil \\ Cesar Augusto Piccinini \\ Universidade Federal do Rio Grande do Sul \\ Jonathan R. H. Tudge \\ University of North Carolina at Greensboro
}

\begin{abstract}
RESUMO - Este estudo investigou as práticas educativas indutivas, coercitivas e de não interferência maternas e paternas aos 24 e 72 meses de vida da criança. Participaram 24 mães e pais de um único filho/a, que responderam uma entrevista para avaliação dessas práticas. Análises estatísticas revelaram que as mães foram significativamente mais indutivas que os pais aos 24 meses, mas aos 72 meses não houve diferenças. Enfatiza-se que as mães tendem a conversar mais com seus filhos/ as, expressar sentimentos, opiniões, estabelecer limites e elogiar comportamentos adequados. As mães também apresentaram médias mais elevadas no total de práticas relatadas, o que pode ser explicado pelo papel predominante que ainda exercem na socialização infantil, embora os pais venham participando mais da educação dos filhos/as.
\end{abstract}

Palavras-chave: Parentalidade; práticas educativas maternas e paternas.

\section{Child-rearing Practices of Mothers and Fathers with 24- and 72-month-old Children}

\begin{abstract}
The present study investigated mothers' and fathers' inductive, coercive and non-interference child-rearing practices with 24- and 72-month-old children. Twenty-four mothers and fathers with an only child were interviewed about their child-rearing practices. Statistical analyses revealed that the mothers described significantly more inductive practices than did the fathers at 24 months, but at 72 months there were no differences. These results indicate that the mothers talked, expressed feelings and opinions, established limits and praised appropriate behaviors more with their children. The mothers, on average, also used a greater total of child-rearing practices than did fathers, which can be explained by the predominant role that they still exercise in the children's socialization, although fathers are participating more in their children's education.
\end{abstract}

Keywords: Parenthood; child-rearing practices of mothers and fathers.

Durante a primeira e a segunda infância, a criança adquire, mais ativa e rapidamente, um padrão de comportamento social e os pais são os responsáveis por oferecer a base necessária para a sua socialização, a partir da promoção de um ambiente incentivador e seguro, no qual a criança possa aprender e se desenvolver (Grusec \& Lytton, 1988). Esse processo envolve exigências dos pais em relação aos filhos/ as, como a transmissão de valores, a administração de afeto e atenção e a restrição a alguns de seus comportamentos (Bandura \& Walters, 1959). Desse modo, as diversas estratégias e técnicas que as mães e os pais usam para orientar os comportamentos de seus filhos/as, enquanto agentes de socialização, têm sido nomeadas por diversos autores como práticas educativas parentais (Mussen, Conger, Kagan \& Huston, 1995; Newcombe, 1996/1999).

1 Artigo derivado da tese de doutorado de Angela Helena Marin, realizada sob a supervisão de Cesar Augusto Piccinini e Jonathan Tudge, apresentada no Programa de Pós-Graduação em Psicologia da Universidade Federal do Rio Grande do Sul, Porto Alegre, RS. Agradecemos ao $\mathrm{CNPq}$ e a Spencer Foundation (financiamento ao último autor) pelo auxílio financeiro recebido.

2 Endereço para correspondência: Avenida Lavras, 654/601. Bairro Petrópolis. Porto Alegre, RS. CEP 90460-040.E-mail: ahmarin@ hotmail.com.
Uma concepção teórica que se destaca acerca das estratégias empregadas pelos pais na socialização das crianças é a de Hoffman $(1975,1994)$, que apontou dois tipos de práticas educativas para modificar o comportamento dos filhos/as: as indutivas e as coercitivas. As práticas indutivas, segundo Hoffman $(1975,1994)$, caracterizam-se por atingir o objetivo disciplinar indicando à criança as consequências do seu comportamento para as outras pessoas e chamando sua atenção para os aspectos lógicos da situação, ao invés das consequências punitivas para ela mesma. Isso propicia à criança a compreensão das implicações de suas ações e, por isso, dos motivos que justificam a necessidade de mudança no seu comportamento. As práticas coercitivas, por sua vez, caracterizam-se pela aplicação direta da força e do poder dos pais, incluindo punição física, privação de privilégios e afeto ou uso de ameaças. Essas estratégias fazem com que a criança controle seu comportamento em função das reações punitivas dos pais. Além disso, elas produzem emoções intensas, como medo, raiva e ansiedade, que tendem a reduzir a possibilidade de a criança compreender a situação e a necessidade de modificação do seu comportamento.

Tendo em vista que o uso dessas práticas está associado ao comportamento dos pais, torna-se relevante considerar 
que o gênero dos mesmos possa ter um impacto específico nestes comportamentos (Belsky, 1984). Ainda se verifica na literatura uma predominância de investigações sobre as práticas educativas maternas, embora o pai venha sendo mais considerado, e os estudos têm revelado tanto semelhanças quanto diferenças na forma como mães e pais tendem a lidar com seus filhos/as. Por exemplo, Bentley e Fox (1991) encontraram similaridades no modo como mães e pais cuidavam das crianças entre um e quatro anos, o que tendia a se manter mesmo quando elas atingiam a idade pré-escolar (Hart, DeWolf, Wozniak \& Burts, 1992). Nessa mesma direção, um estudo com 239 famílias paranaenses, realizado por Weber, Prado, Viezzer e Bradenburg (2004), apresentou semelhanças nos estilos educativos de mães e pais de crianças de nove a 12 anos, avaliados por meio de questionários. Também não foram encontradas diferenças no envolvimento de mães e pais paulistanos na educação de seus filhos, num estudo realizado por Cia, Pereira, Del Prette e Del Prette (2006), com base em questionários padronizados. A mesma tendência foi revelada no estudo de Piccinini, Frizzo, Alvarenga, Lopes e Tudge (2007) ao avaliarem as práticas educativas de mães e pais de crianças com 18 meses de idade por meio de entrevistas sobre situações do dia-a-dia de famílias gaúchas. Tanto as mães, como os pais privilegiaram as explicações como a melhor maneira de disciplinar as suas crianças. Tal semelhança, segundo os autores, pode indicar que os fatores que influenciam na escolha das práticas educativas, como as crenças e valores parentais, a experiência com seus próprios cuidadores, as características das crianças e a situação específica que exige intervenção parecem ser mais relevantes do que as questões de gênero dos próprios pais ou da criança.

Por outro lado, Bolsoni-Silva e Del Prette (2002) indicaram que mães paulistanas tendiam a conversar mais com seus filhos/as, bem como a expressar mais sentimentos e opiniões, estabelecer limites e elogiar comportamentos adequados, quando comparadas aos pais. Particularmente, em relação às práticas educativas utilizadas, essas mães, mais do que os pais, confessaram que tendiam a bater, colocar de castigo e fazer ameaças, apesar de buscarem conversar e solicitar a mudança de comportamento antes de aplicar a estratégia coercitiva. Uma possível explicação para tal evidência é que a tarefa de estabelecer limites e educar os filhos/as, em geral, caberia mais à mãe do que ao pai, e isso a levaria a usar mais intensamente às práticas educativas. Weber, Viezzer e Brandenburg (2004) também indicaram que as mães paranaenses tenderam a utilizar a punição corporal como método disciplinar com maior frequência do que os pais, em uma pesquisa fundamentada nas respostas a questionários de 472 crianças e adolescentes. Os autores sugeriram que talvez isso ocorra pelo fato de normalmente serem as mães as pessoas que mais se ocupam com a disciplina de seus filhos/as. Assim, é plausível supor que as práticas educativas maternas tendem a ter maior impacto no desenvolvimento da criança do que as práticas educativas paternas. Uma possível explicação para tal fato é que as práticas dos pais parecem ser mediadas pelas mães devido a estas ainda serem as maiores responsáveis pelo cuidado e supervisão dos filhos/as (Brook, Zheng, Whiteman \& Brook, 2001; Silveira, Pacheco, Cruz e Schneider, 2005).
Nessa mesma direção, um estudo realizado por Braz, Dessen e Silva (2005) com 14 famílias brasilienses de classes média e baixa, compostas por mãe, pai e criança com idades entre quatro e cinco anos, também indicou que mães e pais apresentaram-se diferentes quanto ao uso das práticas de socialização infantil. Contudo, os pais foram os que mais tenderam a usar a punição verbal, ao passo que as mães tendiam a inibir a liberdade e a negar com mais frequencia algo desejado pelas crianças. Esses achados foram corroborados pelos encontrados por By Fu e Zengh (2008), que mostraram que os pais tendiam a fazer uso de mais controle coercitivo do que as mães na tentativa de controlar o comportamento da criança. Os pais pareciam restringir e/ou incentivar mais a autonomia das crianças, o que podia levá-los a serem mais intrusivos quanto ao seu comportamento, assinalando o que deveria e não deveria ser feito, mesmo em situações em que elas deveriam ser capazes de agir de forma independente (Hastings, Rubin \& DeRose, 2005).

Frente ao exposto, destaca-se que as diferenças nos relatos de mães e pais quanto ao emprego de estratégias de socialização e ao que seria uma educação adequada ou inadequada denotam um movimento em direção às transformações do papel paterno, conforme sugerido por diversos autores (Lewis \& Dessen, 1999; Wagner, Predebon, Mosmann \& Verza, 2005), embora as mães ainda sejam apontadas como as principais responsáveis pelas atividades relativas ao cuidado dos filhos/as e pela execução das tarefas domésticas (Wagner, 2003), bem como mais envolvidas emocionalmente com a parentalidade (Mills. et al, 2007; Rouyer, Frascarolo, Zaouche-Gaudron \& Lavanchy, 2007). Assim, o objetivo do presente estudo consistiu em investigar as práticas educativas maternas e paternas, em particular o uso de práticas indutivas, coercitivas e de não interferência aos 24 e 72 meses de vida da criança, examinando as eventuais diferenças entre as práticas relatadas pelas mães e pelos pais.

\section{Método}

\section{Participantes}

Participaram deste estudo 24 famílias constituídas por mãe, pai e seu primeiro filho/a, que tinha 24 meses de idade no início deste estudo. As mães tinham idade média de 29,5 anos $(\mathrm{DP}=6,9)$ e os pais 27,2 anos $(\mathrm{DP}=5,7)$. Em termos de escolaridade das mães, houve uma variação entre o ensino fundamental incompleto (22\%) e completo (12\%), ensino médio incompleto ( $12 \%$ ) e completo $(25 \%)$ e ensino superior incompleto (12\%) e completo (17\%). A escolaridade dos pais também variou entre o ensino fundamental incompleto (34\%) e completo $(8 \%)$, ensino médio incompleto (4\%) e completo (29\%) e ensino superior incompleto $(21 \%)$ e completo $(4 \%)$. Já quanto ao sexo da criança, 54\% eram meninos e $46 \%$ meninas. Em relação ao nível socioeconômico da família, que foi calculado com base no nível educacional e ocupacional das mães e dos pais (Hollingshead, 1975, adaptado por Tudge \& Frizzo, 2002), a variação ocorreu entre o nível baixo (21\%), 
o médio-baixo (21\%), o médio (29\%), o médio-alto $(21 \%)$ e o alto $(8 \%)^{3}$.

A amostra foi selecionada dentre os participantes do Estudo Longitudinal de Porto Alegre: Da Gestação à Escola - ELPA ${ }^{4}$ (Piccinini, Tudge, Lopes \& Sperb, 1998). Este estudo iniciou acompanhando 81 gestantes que não apresentavam intercorrências clínicas e que estavam esperando seu primeiro filho/a, juntamente com seus maridos ou companheiros, caso residissem em situação matrimonial. Os bebês, nascidos a termo, também não apresentavam problemas de saúde. Os participantes representavam várias configurações familiares (nucleares, uniparentais ou recasados), diferentes idades (adultos e adolescentes) e escolaridade e níveis socioeconômicos variados. Para fins do presente estudo, foram escolhidos todos os casos cujos pais viviam juntos, tendo ou não oficializado a união, e que tinham dados completos aos 24 e 72 meses de vida da criança, totalizando as 24 famílias descritas acima.

\section{Delineamento, Procedimentos e Instrumentos}

Foi utilizado um delineamento longitudinal (Mussen, 1992) para se investigar as práticas educativas maternas e paternas, particularmente o uso de práticas indutivas, coercitivas e de não interferência aos 24 e 72 meses de vida da criança, examinando as eventuais diferenças entre as práticas relatadas pelas mães e pelos pais.

O presente estudo considerou apenas duas das diversas fases de coleta de dados do ELPA detalhadas em Piccinini et al. (1998) e que serão destacadas a seguir. No início do referido estudo, quando as gestantes estavam no terceiro trimestre de gestação, elas preencheram a Ficha de Contato Inicial (GIDEP, 1998a), informando alguns dados sociodemográficos sobre o casal. Os casais que preencheram os critérios do estudo (estar esperando o primeiro filho/a, estar no terceiro trimestre de gestação e não apresentar complicações físicas durante a gravidez) foram contatados, posteriormente, por telefone para agendar uma visita domiciliar. Durante essa visita, foram preenchidos o Termo de Consentimento Livre e Esclarecido e a Entrevista de Dados Demográficos (GIDEP,

3 Esse cálculo considera três fatores: educação, ocupação, estado civil das mães e dos pais. Desses fatores derivam as seguintes categorias: Nível 1 - trabalhadores sem habilidades, empregados domésticos; Nível 2 operadores de máquinas, trabalhadores com poucas habilidades; Nível 3 - trabalhadores com habilidades, auxiliares de escritório, balconistas; Nível 4 - proprietários de empresas de médio porte, técnicos; Nível 5 - proprietários de grandes empresas e profissionais de nível superior.

4 O estudo envolve várias fases de coletas de dados realizadas desde a gestação até os oito anos de vida das crianças (gestação, $3^{\circ}, 8^{\circ}, 12^{\circ}, 18^{\circ}$, $24^{\circ}, 36^{\circ}$ mês e 6o $7^{\circ}$ e e $8^{\circ}$ ano de vida da criança). O objetivo é investigar tanto os aspectos subjetivos e comportamentais das interações iniciais mãe-pai-bebê, assim como o impacto de fatores iniciais do desenvolvimento nas interações familiares, no comportamento social de crianças pré-escolares e na transição para a escola de ensino fundamental. $\mathrm{O}$ convite inicial para participar do estudo ocorreu quando a gestante fazia o pré-natal em hospitais da rede pública da cidade de Porto Alegre $(51,2 \%)$, nas unidades sanitárias de saúde do mesmo município (7,4\%), por meio de anúncio em veículos de comunicação $(26,8 \%)$ e por indicação $(14,6 \%)$ 1998b). Quando as crianças completaram 24 meses, as famílias foram novamente contatadas por telefone e convidadas a comparecer ao Instituto de Psicologia da UFRGS. Nessa ocasião, foi realizada a Entrevista sobre Práticas Educativas Parentais (Piccinini \& Alvarenga, 2000), para a avaliação das práticas educativas utilizadas pelas mães e pelos pais ${ }^{5}$. Aos 72 meses de vida da criança, as famílias foram contatadas para uma nova coleta de dados, que consistiu em uma visita em suas residências quando se reaplicou a Entrevista sobre Práticas Educativas Parentais. Essa entrevista é estruturada com questões abertas que buscam investigar as práticas educativas utilizadas pela mãe e pelo pai na regulação do comportamento dos seus filhos/as (Hart, Ladd \& Burleson, 1990; Piccinini, Maggi \& Carro, 1993). Ela consiste em seis situações cotidianas, as quais têm sido apontadas como propícias à ocorrência de práticas educativas e que podem envolver comportamentos inadequados e de desobediência da criança, como, por exemplo: recusar-se a comer; recusar-se a entrar/sair do banho; recusar-se a trocar de roupa; recusar-se a dormir à noite; fazer birra quando recebe um não dos pais; e recusar-se a ficar com outra pessoa, que não seja a sua mãe ou o seu pai. Aos 72 meses, duas alterações foram feitas, no sentido de acompanhar a etapa do desenvolvimento das crianças. A situação "a criança recusa-se a trocar de roupa", foi adaptada para "a criança insiste em vestir algumas roupas prediletas"; e a situação "a criança recusa-se a ficar com outra pessoa, que não seja sua mãe ou seu pai” foi modificada para "a criança recusa-se a ir/voltar da creche/ escola" na hora prevista.

As entrevistas, realizadas separadamente com a mãe e com o pai, foram gravadas em áudio e transcritas para fins de análise, sendo examinadas por meio de análise de conteúdo quantitativa (Bardin, 1977). Com base em Hoffman $(1975,1994)$, e considerando as sugestões de Alvarenga e Piccinini (2003), as práticas educativas foram classificadas como: indutivas, que envolve as subcategorias negocia/troca, explica/fala, explica baseado em convenções/consequências, organiza o ambiente/forma hábito e comanda sem coerção; e coercitivas, que envolve as subcategorias punição, ameaça, coação física, punição física. Além dessas categorias, foi incluída uma terceira, denominada não interferência, que envolve as subcategorias não se intromete, segue o ritmo da criança e cede à vontade da criança (Piccinini et al., 2007). Ainda, algumas estratégias educativas não se enquadraram nas categorias mencionadas acima e foram denominadas outras, que inclui as subcategorias pede ajuda para outra pessoa e engana.

O índice de fidedignidade entre os juízes foi calculado utilizando o Coeficiente Kappa em $20 \%$ das respostas de mães e pais para as entrevistas realizadas em cada uma das etapas de coleta de dados, considerando as três principais categorias de práticas educativas ${ }^{6}$. Aos 24 meses, o índice de

5 Parte desses dados foi analisada por Alvarenga, Piccinini, Frizzo, Lopes e Tudge (2009), em um estudo que comparou as práticas educativas parentais entre os 18 e 24 meses de vida da criança. O presente estudo estende essas análises, considerando também os 72 meses de vida da criança.

6 Tendo em vista a variação de respostas quanto às práticas educativas, o Coeficiente Kappa foi calculado considerando apenas as grandes 
fidedignidade foi de 0,77 para as mães e 0,84 para os pais. Aos 72 meses, o índice de fidedignidade atingiu 0,97 para as mães e 0,98 para os pais. Esses índices são considerados excelentes por Robson (1995) ${ }^{7}$.

\section{Resultados}

A análise de conteúdo quantitativa foi utilizada para examinar a frequência e o percentual das práticas educativas maternas e paternas para cada uma das situações específicas investigadas na Entrevista sobre Práticas Educativas Parentais, realizada aos 24 e 72 meses de vida da criança.

\section{Práticas Educativas Maternas}

A Tabela 1 apresenta as porcentagens e frequências das práticas educativas maternas relatadas aos 24 e 72 meses de vida da criança.

Como pode ser observado, aos 24 meses, as práticas indutivas (48\%) foram as mais mencionadas pelas mães, seguidas das práticas coercitivas $(30,9 \%)$ e das práticas de não interferência (18\%). Quando analisadas as situações específicas, as práticas indutivas também foram mais frequentemente utilizadas nas situações: ficar com outra pessoa (63\%), dormir (59\%), banho (49\%) e trocar de roupa (47\%). As práticas coercitivas, por sua vez, foram bastante utilizadas nas situações envolvendo a birra (49\%), o trocar de roupa $(40 \%)$ e o banho (30\%). Já as práticas de não interferência foram mais utilizadas nas situações como o comer (39\%), o ficar com outra pessoa $(27 \%)$ e o dormir $(24 \%)$. Por fim, avaliando o total de práticas educativas utilizadas, as situações que requereram maior intervenção foram a birra (21\%), o banho $(18 \%)$ e a troca de roupa (17\%).

Quanto às subcategorias, entre as práticas indutivas, as mais referidas pelas mães foram o negocia/troca $(20 \%)$, o explica/fala (13\%) e o explica baseado em convenções/consequências $(7 \%)$. No que tange às subcategorias de práticas coercitivas, as mães relataram utilizar mais punição $(10 \%)$, punição física (5\%) e ameaça (5\%). Por fim, as subcategorias de práticas de não interferência foram utilizadas de modo equilibrado: não se intromete $(6 \%)$, cede à vontade da criança $(6 \%)$ e segue o ritmo da criança $(5 \%)$.

Aos 72 meses de vida da criança, as mães apresentaram também um maior número de práticas indutivas (46\%), seguidas das práticas coercitivas (32\%) e das práticas de não interferência $(20 \%)$. No que diz respeito ao uso das práticas educativas nas situações específicas, as práticas indutivas foram as mais utilizadas nas situações envolvendo o trocar de roupa (54\%), a escola (53\%), o dormir (49\%) e a birra (47\%). Já as práticas coercitivas foram mais ressaltadas na situação do banho (46\%) e do comer (37\%). As práticas de

categorias (indutividade, coerção e não interferência) para cada uma das situações investigadas.

7 De acordo com Robson (1995), os valores do Coeficiente Kappa são assim classificados: suficientes $(0,40$ a 0,60$)$, bons $(0,60$ a 0,75$)$ e excelentes (acima de 0,75 ). não interferência, por sua vez, foram mais mencionadas nas situações envolvendo o dormir (31\%), o comer (29\%) e a birra (22\%). Constata-se que as situações que exigiram um maior número de práticas educativas foram aquelas envolvendo o comer $(20 \%)$, o trocar de roupa (18\%) e o banho (17\%).

No que diz respeito às subcategorias de práticas educativas utilizadas, destaca-se que, entre as práticas indutivas, as mais referidas pelas mães foram: explica/fala (18\%), negocia/ troca $(10 \%)$ e comando verbal sem coerção $(7 \%)$. Já quanto às subcategorias de práticas coercitivas, elas referiram mais a punição $(22 \%)$, a ameaça $(6 \%$ e $3 \%)$ e a coação física ( $4 \%$ e $3 \%$ ). No que tange às subcategorias de práticas de não interferência, as mães referiram ceder à vontade da criança $(12 \%)$, não se intrometer (8\%) e seguir o ritmo da criança (1\%).

\section{Práticas Educativas Paternas}

A Tabela 2 apresenta as porcentagens e frequências das práticas educativas paternas aos 24 e 72 meses de vida da criança.

Como pode ser visto, os pais relataram com maior frequência as práticas indutivas (38\%), seguidas pelas práticas de não interferência (29\%) e coercitivas (27\%). Quanto às situações examinadas, as práticas indutivas foram bastante mencionadas, principalmente nas situações envolvendo o trocar de roupa (53\%), o ficar com outra pessoa (48\%), o tomar banho $(43 \%)$ e o dormir (41\%). Já as práticas coercitivas predominaram nas seguintes situações: birra (51\%), banho $(36 \%)$ e trocar de roupa $(30 \%)$. Por fim, as práticas de não interferência foram mais salientes na situação do comer (51\%), ficar com outra pessoa (40\%) e dormir (38\%). Entre as situações, os pais mencionaram um maior número de práticas educativas para birra (23\%), comer $(19 \%)$ e trocar de roupa $(16 \%)$.

Quanto às subcategorias, entre as práticas indutivas, os pais relataram mais as subcategorias negocia/troca $(20 \%)$ e explica/fala $(10 \%)$. No tocante às subcategorias de práticas coercitivas, os pais destacaram o uso da punição (11\%), da coação física ( $9 \%$ ) e da ameaça (4\%). Por fim, quanto às subcategorias de práticas de não interferência, os pais relataram ceder mais à vontade da criança $(13 \%)$, assim como seguir seu ritmo (9\%) e não se intrometer (7\%).

Aos 72 meses de vida da criança, foi possível constatar que os pais utilizaram um maior número de práticas indutivas (46\%), acompanhadas das práticas coercitivas (28\%) e das práticas de não interferência (25\%). Considerando as situações examinadas, destaca-se que as práticas indutivas foram as mais salientes na maioria delas, principalmente para o dormir (59\%), a escola (57\%), a birra (54\%) e o comer (37\%). Já no que diz respeito às práticas coercitivas, destacaram-se as situações envolvendo o banho (56\%), a birra $(34 \%)$ e o comer $(25 \%)$. No tocante às práticas de não interferência, elas foram mais frequentes nas situações como o trocar de roupa (43\%), o comer (36\%) e o dormir $(28,6 \%)$. Observa-se também que aquelas situações que exigiram o uso de um maior número total de práticas educativas foram o comer $(21 \%)$, o banho (18\%), o trocar de roupa $(17 \%)$ e a birra $(17 \%)$. 
Tabela 1. Porcentagens e Frequências (entre parênteses) das Práticas Educativas Maternas aos 24 e 72 Meses de Vida da Criança (n=24)

\begin{tabular}{|c|c|c|c|c|c|c|c|c|}
\hline \multirow[b]{2}{*}{ Práticas educativas } & \multicolumn{8}{|c|}{ Situações } \\
\hline & & Comer & Banho & Roupa & Dormir & Birra & Pessoa/Esc. & Total \\
\hline \multirow[t]{2}{*}{ Indutivas } & $24 \mathrm{~m}$ & 37 (14) & $49(21)$ & 47 (19) & $59(22)$ & $39(19)$ & $63(19)$ & 48 (114) \\
\hline & $72 \mathrm{~m}$ & $30(18)$ & $44(23)$ & $54(29)$ & $49(24)$ & $47(21)$ & $53(23)$ & $46(138)$ \\
\hline \multirow[t]{2}{*}{ Negocia/troca } & $24 \mathrm{~m}$ & $32(12)$ & $30(13)$ & $25(10)$ & $11(4)$ & $10(5)$ & $10(3)$ & $20(47)$ \\
\hline & $72 \mathrm{~m}$ & $10(6)$ & $21(11)$ & $13(7)$ & $4(2)$ & $11(5)$ & - & $10(31)$ \\
\hline \multirow[t]{2}{*}{ Explica/fala } & $24 \mathrm{~m}$ & - & $9(4)$ & $10(4)$ & $8(3)$ & $12(6)$ & 47 (14) & $13(31)$ \\
\hline & $72 \mathrm{~m}$ & $7(4)$ & $4(2)$ & $26(14)$ & $8(4)$ & $29(13)$ & $44(19)$ & $18(56)$ \\
\hline \multirow{2}{*}{ Explica bas. conv./conseq. } & $24 \mathrm{~m}$ & $5(2)$ & $5(2)$ & $7(3)$ & - & $16(8)$ & $7(2)$ & $7(17)$ \\
\hline & $72 \mathrm{~m}$ & $5(3)$ & $6(3)$ & $9(5)$ & $2(1)$ & - & $5(2)$ & $5(14)$ \\
\hline \multirow[t]{2}{*}{ Organiza ambiente } & $24 \mathrm{~m}$ & - & - & - & $35(13)$ & - & - & $5(13)$ \\
\hline & $72 \mathrm{~m}$ & $2(1)$ & - & - & $29(14)$ & - & - & $5(15)$ \\
\hline \multirow[t]{2}{*}{ Comando verbal s/ coerção } & $24 \mathrm{~m}$ & - & $5(2)$ & $5(2)$ & $5(2)$ & - & - & $2(6)$ \\
\hline & $72 \mathrm{~m}$ & $7(4)$ & $3(7)$ & $5(3)$ & $6(3)$ & $7(3)$ & $5(2)$ & $7(22)$ \\
\hline \multirow[t]{2}{*}{ Coercitivas } & $24 \mathrm{~m}$ & 24 ( 9) & $30(13)$ & $40(16)$ & $16(6)$ & $49(24)$ & $10(3)$ & $30(71)$ \\
\hline & $72 \mathrm{~m}$ & $37(22)$ & $46(24)$ & $26(14)$ & $20(10)$ & $31(14)$ & $30(13)$ & $32(97)$ \\
\hline \multirow[t]{2}{*}{ Punição } & $24 \mathrm{~m}$ & $16(6)$ & $7(3)$ & $10(4)$ & $8(3)$ & $14(7)$ & $3(1)$ & $10(24)$ \\
\hline & $72 \mathrm{~m}$ & $20(12)$ & $29(15)$ & $24(13)$ & $12(6)$ & $22(10)$ & $28(12)$ & $22(68)$ \\
\hline \multirow[t]{2}{*}{ Ameaça } & $24 \mathrm{~m}$ & $5(2)$ & - & - & $5(2)$ & $14(7)$ & - & $5(11)$ \\
\hline & $72 \mathrm{~m}$ & $15(9)$ & $4(2)$ & $2(1)$ & $4(2)$ & $7(3)$ & - & $6(17)$ \\
\hline \multirow[t]{2}{*}{ Coação física } & $24 \mathrm{~m}$ & - & $23(10)$ & $22(9)$ & $3(1)$ & $6(3)$ & $3(1)$ & $10(24)$ \\
\hline & $72 \mathrm{~m}$ & $2(1)$ & $3(7)$ & - & $4(2)$ & - & $2(1)$ & $4(11)$ \\
\hline \multirow[t]{2}{*}{ Punição física } & $24 \mathrm{~m}$ & $3(1)$ & - & $7(3)$ & - & $14(7)$ & $3(1)$ & $5(12)$ \\
\hline & $72 \mathrm{~m}$ & - & - & - & - & $2(1)$ & - & $0,3(1)$ \\
\hline \multirow[t]{2}{*}{ Não interferência } & $24 \mathrm{~m}$ & $39(15)$ & $21(6)$ & $12(4)$ & $24(9)$ & $12(6)$ & $27(2)$ & $18(42)$ \\
\hline & $72 \mathrm{~m}$ & $29(17)$ & $10(5)$ & $18(10)$ & $31(15)$ & $22(10)$ & $16(7)$ & $20(62)$ \\
\hline \multirow[t]{2}{*}{ Não se intromete } & $24 \mathrm{~m}$ & $10(4)$ & - & $5(2)$ & $8(3)$ & $10(5)$ & $3(1)$ & $6(15)$ \\
\hline & $72 \mathrm{~m}$ & 5 (9) & - & $4(2)$ & $16(8)$ & $9(4)$ & - & $8(23)$ \\
\hline \multirow[t]{2}{*}{ Cede à vontade da criança } & $24 \mathrm{~m}$ & $10(4)$ & $7(3)$ & $5(2)$ & $8(3)$ & $2(1)$ & $3(1)$ & $6(14)$ \\
\hline & $72 \mathrm{~m}$ & $10(6)$ & $10(5)$ & $15(8)$ & $12(6)$ & $11(5)$ & $14(6)$ & $12(36)$ \\
\hline \multirow[t]{2}{*}{ Segue o ritmo da criança } & $24 \mathrm{~m}$ & $18(7)$ & $7(3)$ & - & $8(3)$ & - & - & $5(13)$ \\
\hline & $72 \mathrm{~m}$ & $3(2)$ & - & - & $2(1)$ & - & - & $1(3)$ \\
\hline \multirow[t]{2}{*}{ Outras } & $24 \mathrm{~m}$ & - & $7(3)$ & $2(1)$ & - & - & $20(6)$ & $4(10)$ \\
\hline & $72 \mathrm{~m}$ & $3(2)$ & - & $2(1)$ & - & $2(1)$ & $2(1)$ & $2(5)$ \\
\hline \multirow[t]{2}{*}{ Total } & $24 \mathrm{~m}$ & $16(38)$ & $18(43)$ & $17(40)$ & $15(37)$ & $21(49)$ & $13(30)$ & $100(237)$ \\
\hline & $72 \mathrm{~m}$ & $20(59)$ & $17(52)$ & $18(54)$ & $16(49)$ & $15(45)$ & $14(43)$ & $100(302)$ \\
\hline
\end{tabular}

No que tange às subcategorias de práticas educativas utilizadas, destaca-se que, entre as práticas indutivas, os pais relataram utilizar o explica/fala (19\%), o negocia/troca $(9 \%)$ e o comando verbal sem coerção $(8 \%)$. Já quanto às subcategorias de práticas coercitivas, eles referiram mais a punição $(22 \%)$, a ameaça $(3 \%)$ e a coação física $(3 \%)$. No tocante às subcategorias de práticas de não interferência, os pais referiram ceder à vontade da criança $(11 \%)$, não se intrometer (11\%) e seguir o ritmo da criança $(3 \%)$.

Para examinar as eventuais diferenças nas práticas educativas relatadas pelas mães e pelos pais em cada fase investigada, utilizou-se o teste não-paramétrico Wilcoxon. A Tabela 3 apresenta o valor da mediana, o intervalo interquartílico, o desvio padrão e o nível de significância das práticas educativas maternas e paternas aos 24 e 72 meses de vida da criança.

Aos 24 meses, as análises revelaram uma diferença significativa para as práticas indutivas $(\mathrm{p}<0,007)$, indicando que as mães (mediana: 4; intervalo interquartílico: 3-7) são mais indutivas do que os pais (mediana: 3 ; intervalo interquartílico: 2-4). Já aos 72 meses não foram encontradas diferenças significativas entre as mães e os pais. 
Tabela 2. Porcentagens e Frequências (entre parênteses) das Práticas Educativas Paternas aos 24 e 72 Meses de Vida da Criança (n=24)

\begin{tabular}{|c|c|c|c|c|c|c|c|c|}
\hline \multirow[b]{2}{*}{ Práticas educativas } & \multicolumn{8}{|c|}{ Situações } \\
\hline & & Comer & Banho & Roupa & Dormir & Birra & $\begin{array}{c}\text { Pessoa/ } \\
\text { Esc. }\end{array}$ & Total \\
\hline \multirow[t]{2}{*}{ Indutivas } & $24 m$ & $29(10)$ & $43(12)$ & $53(16)$ & $41(12)$ & $23(10)$ & $48(12)$ & $38(72)$ \\
\hline & $72 \mathrm{~m}$ & $37(21)$ & $33(16)$ & $41(18)$ & $59(25)$ & $54(24)$ & $57(17)$ & $46(121)$ \\
\hline \multirow[t]{2}{*}{ Negocia/troca } & $24 \mathrm{~m}$ & $20(7)$ & $29(8)$ & $37(11)$ & $14(4)$ & $7(3)$ & $20(5)$ & $20(38)$ \\
\hline & $72 \mathrm{~m}$ & $14(8)$ & $6(3)$ & $9(4)$ & $7(3)$ & $11(5)$ & $7(2)$ & $9(25)$ \\
\hline \multirow[t]{2}{*}{ Explica/fala } & $24 \mathrm{~m}$ & $3(1)$ & $11(3)$ & $10(3)$ & $3(1)$ & $12(5)$ & $8(7)$ & $10(20)$ \\
\hline & $72 \mathrm{~m}$ & $11(6)$ & $8(4)$ & $23(10)$ & $5(2)$ & $36(16)$ & $40(12)$ & $19(50)$ \\
\hline \multirow[t]{2}{*}{ Explica bas. conv./conseq. } & $24 \mathrm{~m}$ & - & $4(1)$ & - & - & $2(1)$ & - & $1(2)$ \\
\hline & $72 \mathrm{~m}$ & $5(3)$ & $4(2)$ & - & $9(4)$ & - & $7(2)$ & $4(11)$ \\
\hline \multirow[t]{2}{*}{ Organiza ambiente } & $24 \mathrm{~m}$ & - & - & - & $17(5)$ & - & - & $3(5)$ \\
\hline & $72 \mathrm{~m}$ & - & - & $9(4)$ & 21 ( 9$)$ & - & - & $5(13)$ \\
\hline \multirow[t]{2}{*}{ Comando verbal s/ coerção } & $24 \mathrm{~m}$ & $6(2)$ & - & $7(2)$ & $7(2)$ & $2(1)$ & - & $4(7)$ \\
\hline & $72 \mathrm{~m}$ & $7(4)$ & $15(7)$ & - & $17(7)$ & $7(3)$ & $3(1)$ & $8(22)$ \\
\hline \multirow[t]{2}{*}{ Coercitivas } & $24 \mathrm{~m}$ & $17(6)$ & $36(10)$ & $30(9)$ & $14(4)$ & $51(22)$ & $4(1)$ & $27(52)$ \\
\hline & $72 \mathrm{~m}$ & $25(14)$ & $56(27)$ & $16(7)$ & $12(5)$ & $34(15)$ & $23(7)$ & $28(75)$ \\
\hline \multirow[t]{2}{*}{ Punição } & $24 \mathrm{~m}$ & $11(4)$ & - & $10(3)$ & $7(2)$ & $26(11)$ & $4(1)$ & $11(21)$ \\
\hline & $72 \mathrm{~m}$ & $20(11)$ & $42(20)$ & $16(7)$ & $9(4)$ & $20(9)$ & $23(7)$ & $22(58)$ \\
\hline \multirow[t]{2}{*}{ Ameaça } & $24 \mathrm{~m}$ & $6(2)$ & $7(2)$ & $3(1)$ & $3(1)$ & $5(2)$ & - & $4(8)$ \\
\hline & $72 \mathrm{~m}$ & $5(3)$ & $4(2)$ & - & - & $7(3)$ & - & $3(8)$ \\
\hline \multirow[t]{2}{*}{ Coação física } & $24 \mathrm{~m}$ & - & $29(8)$ & $13(4)$ & $3(1)$ & $9(4)$ & - & $9(17)$ \\
\hline & $72 \mathrm{~m}$ & - & $8(4)$ & - & $2(1)$ & $4(2)$ & - & $3(7)$ \\
\hline \multirow[t]{2}{*}{ Punição física } & $24 \mathrm{~m}$ & - & - & $3(1)$ & - & $12(5)$ & - & $3(6)$ \\
\hline & $72 \mathrm{~m}$ & - & $2(1)$ & - & - & $2(1)$ & - & $1(2)$ \\
\hline \multirow[t]{2}{*}{ Não interferência } & $24 m$ & $51(18)$ & $18(5)$ & $10(3)$ & $38(11)$ & $21(9)$ & $40(10)$ & $29(56)$ \\
\hline & $72 \mathrm{~m}$ & $36(20)$ & $10(5)$ & $43(19)$ & $29(12)$ & $11(5)$ & $17(5)$ & $25(66)$ \\
\hline \multirow[t]{2}{*}{ Não se intromete } & $24 \mathrm{~m}$ & $9(3)$ & $4(1)$ & $3(1)$ & $3(1)$ & $9(4)$ & $16(4)$ & $7(14)$ \\
\hline & $72 \mathrm{~m}$ & $12(7)$ & $4(2)$ & $27(12)$ & $12(5)$ & $7(3)$ & - & $11(29)$ \\
\hline \multirow[t]{2}{*}{ Cede à vontade da criança } & $24 \mathrm{~m}$ & $26(9)$ & $7(2)$ & - & $7(5)$ & $12(5)$ & $16(4)$ & $3(25)$ \\
\hline & $72 \mathrm{~m}$ & $12(7)$ & $6(3)$ & $16(7)$ & $12(5)$ & $4(2)$ & $17(5)$ & $1(29)$ \\
\hline \multirow[t]{2}{*}{ Segue o ritmo da criança } & $24 \mathrm{~m}$ & $17(6)$ & $7(2)$ & $7(2)$ & $17(5)$ & - & $8(2)$ & $9(17)$ \\
\hline & $72 \mathrm{~m}$ & $11(6)$ & - & - & $5(2)$ & - & - & $3(8)$ \\
\hline \multirow[t]{2}{*}{ Outras } & $24 \mathrm{~m}$ & $3(1)$ & $4(1)$ & $7(2)$ & $7(2)$ & $5(2)$ & $8(2)$ & $5(10)$ \\
\hline & $72 \mathrm{~m}$ & $2(1)$ & - & - & - & - & $3(1)$ & $1(2)$ \\
\hline \multirow[t]{2}{*}{ Total } & $24 \mathrm{~m}$ & $19(35)$ & $14(28)$ & $16(30)$ & $15(29)$ & $23(43)$ & $13(25)$ & $100(190)$ \\
\hline & $72 \mathrm{~m}$ & $21(56)$ & $18(48)$ & $17(44)$ & $6(42)$ & $17(44)$ & $11(30)$ & $100(264)$ \\
\hline
\end{tabular}

Tabela 3. Mediana, Intervalo Interquartílico (entre parênteses) e Nível de Significância (p) das Práticas Educativas Maternas e Paternas aos 24 e 72 Meses de Vida da Criança $(\mathrm{n}=24)$

\begin{tabular}{lcccc}
\hline Práticas educativas & & Maternas & Paternas & $\boldsymbol{p}$ \\
\hline Indutivas & $24 \mathrm{~m}$ & $4(3-7)$ & $3(2-4)$ & 0,007 \\
& $72 \mathrm{~m}$ & $6(3-8)$ & $4(3-10)$ & 0,68 \\
\hline Coercitivas & $24 \mathrm{~m}$ & $3(2-4)$ & $2(1-4)$ & 0,12 \\
& $72 \mathrm{~m}$ & $4(2-6)$ & $3(1-6)$ & 0,41 \\
\hline Não interferência & $24 \mathrm{~m}$ & $2(1-3)$ & $2(1-4)$ & 0,22 \\
& $72 \mathrm{~m}$ & $2(2-4)$ & $3(1-4)$ & 0,85 \\
\hline
\end{tabular}




\section{Discussão}

O presente estudo investigou as práticas educativas maternas e paternas, em particular as indutivas, coercitivas e de não interferência aos 24 e 72 meses de vida da criança, examinando as eventuais diferenças entre as práticas relatadas pelas mães e pelos pais. No que diz respeito às práticas educativas maternas e paternas aos 24 meses de vida da criança, foi possível constatar que tanto as mães quanto os pais referiram utilizar com maior frequência as práticas indutivas, principalmente a negociação/troca, nas situações do ficar com outra pessoa e do dormir. As práticas coercitivas, por sua vez, foram mais relatadas pelas mães e pelos pais na situação da birra, que tenderia a ser contida por meio da punição física e da coação física. Por fim, destaca-se que, além de terem utilizado um maior número de práticas, as mães também foram significativamente mais indutivas que os pais aos 24 meses de vida da criança.

Em relação às práticas educativas utilizadas aos 72 meses de vida da criança, da mesma forma que no momento anterior, as mães e os pais referiram utilizar mais frequentemente as práticas indutivas, especialmente as práticas referentes ao explica/fala e ao negocia/troca, nas situações do escolher a roupa e de ir/voltar à escola. As práticas coercitivas foram mais referidas nas situações do banho e do comer, por meio da punição e da ameaça. Já as práticas de não interferência foram mais utilizadas na situação do escolher a roupa, na qual as mães e os pais relataram mais frequentemente que cediam à vontade da criança ou não interferiam no seu comportamento. Contudo, na comparação das práticas utilizadas pelas mães e pelos pais, não foram encontradas diferenças significativas.

Tomando os dois momentos analisados em conjunto, constata-se que as práticas indutivas foram predominantemente mais relatadas tanto pelas mães quanto pelos pais. Essa tendência já havia sido apontada por outros estudos (Piccinini et al., 2007; Alvarenga \& Piccinini, 2003; Piccinini, Castro, Alvarenga, Vargas \& Oliveira; 2003; Alvarenga \& Piccinini, 2001), que indicaram que mães e pais privilegiavam as explicações como a melhor maneira de disciplinar as suas crianças, de acordo com suas respostas a mesma entrevista utilizada no presente estudo, examinando diferentes contextos de interação. No contexto internacional, alguns estudos também enfatizaram as similaridades no modo como mães e pais cuidavam de suas crianças (Bentley \& Fox, 1991; Hart. et al., 1992), principalmente quanto ao uso de práticas indutivas.

No tocante às práticas coercitivas, elas também foram mencionadas com frequência nos dois momentos examinados, o que mostra que a coerção representa uma importante estratégia de regulação do comportamento infantil. Destaca-se também que o contexto é sempre importante quando se fala em práticas educativas. De acordo com Biasoli-Alves e Caldana (1992), parecem existir algumas normas para as quais se exige mais prontamente a obediência da criança, como, por exemplo, nas situações envolvendo higiene, saúde ou frente a comportamentos bastante perturbadores, como a birra. Também é importante enfatizar que as práticas coercitivas relacionadas aos cuidados físicos da criança foram mais utilizadas aos 24 meses, o que vai ao encontro da literatura que tem apontado que, à medida que a criança se torna mais velha, os pais tendem a diminuir o uso da coerção (Frick, Christian \& Wootton, 1999).
Também se destacaram os relatos maternos e paternos referentes à atitude de não interferir no comportamento da criança. A opção por não intervir adotada pelas mães e pelos pais em várias das situações investigadas pode ser atribuída à crença parental de que é importante para a criança desenvolver a assertividade e a autonomia, exercendo sua capacidade de decidir e escolher. Nesse sentido, parece haver uma maior valorização da flexibilidade em detrimento da rigidez e do controle parental (Piccinini et al., 2007).

Mesmo que alguns resultados do presente estudo, assim como outros relatados na literatura (Bentley \& Fox, 1991; Cia et al., 2006; Hart et al.,1992; Weber et al., 2004), tenham salientado as similaridades no modo como mães e pais cuidam das crianças, algumas diferenças entre eles também foram encontradas. Por exemplo, as mães se revelaram mais indutivas que os pais aos 24 meses de vida da criança. Tais dados vão ao encontro da literatura que enfatiza o uso mais frequente de práticas de caráter indutivo pelas mães do que pelos pais, tendendo a conversar mais com seus filhos/as, bem como a expressar sentimentos e opiniões, estabelecer limites e elogiar comportamentos adequados (Bolsoni-Silva $\&$ Del Prette, 2002; Braz et al., 2005; Silveira et al., 2005).

Apesar de, no presente estudo, não terem sido encontradas diferenças significativas quanto às práticas coercitivas de mães e pais, alguns autores (Bolsoni-Silva \& Del Prette, 2002; Weber et al., 2004) têm indicado que as mães, mais do que os pais, tendem a surrar, colocar de castigo e fazer ameaças à criança, depois de buscarem conversar e pedir a mudança de comportamento antes de aplicar a estratégia coercitiva. Uma possível explicação para tal evidência é que a tarefa de estabelecer limites e educar os filhos/as, em geral, caberia mais à mãe do que ao pai, e isso a levaria a usar mais do que os pais essas práticas educativas (Mills et al., 2007; Weber et al., 2004). Além disso, as práticas paternas tendem a ser mediadas pelas mães devido a estas ainda serem as maiores responsáveis pelo cuidado e supervisão dos filhos/ as (Brook et at., 2001), o que as levaria a conviverem mais frequentemente com situações potencialmente conflitivas. Isso pode estar sendo refletido também no fato de as mães terem apresentado médias mais elevadas do que os pais quanto ao total de práticas educativas utilizadas. Tal dado pode ser explicado pelo papel predominante que as mulheres ainda exercem no processo de socialização das crianças (Silveira et al., 2005; Wagner, 2003), embora os pais venham participando mais da educação dos filhos/as.

Contudo, é necessário destacar que as eventuais diferenças relatadas no comportamento de mães e pais podem ser o produto de suas diferentes reações ao processo de ser questionado, mais do que de suas diferenças de gênero (Dessen \& Lewis, 1998). Nesse sentido, o conceito de coparentalidade, que diz respeito a como os pais lidam em conjunto com as questões relativas à parentalidade, apóiam um ao outro e administram conflitos quanto à forma de educar suas crianças, tem sido apontado como mais importante que as eventuais diferenças que mães e pais venham a apresentar (Feinberg \& Kan, 2008)

Em suma, ressalta-se que mesmo que as mães e os pais sejam os principais responsáveis pela socialização infantil (Kuczynski \& Grusec, 1997), as suas normas e processos variam segundo uma série de fatores que interagem entre si 
e transcendem a própria família. Em função disso, as práticas educativas parentais precisam ser compreendidas a partir de uma abordagem que considere tanto o sistema familiar como o contexto mais amplo no qual ele está envolvido (Javo, Ronning, Heyerdahl \& Rudmin, 2004; Tudge, 2008).

Por fim, destaca-se que, apesar das limitações do presente estudo, como a amostra reduzida e restrições quanto ao instrumento utilizado, sua contribuição reside em demonstrar as particularidades das práticas educativas maternas e paternas com relação ao contexto em que ocorrem. Também fica clara a complexidade de se investigar as práticas educativas e a necessidade de novos estudos, que contribuam para atender a grande demanda de mães e pais que buscam respostas sobre a melhor forma de educar seus/suas filhos/as. A falta de conhecimentos mais consistentes sobre este tema tem levado muitos deles/as a viverem com insegurança, tendo em vista as inúmeras opções, todas válidas e, ao mesmo tempo, potencialmente criticáveis, quanto ao uso de uma ou outra prática educativa no dia-a-dia com o filho/a. A diversidade nos discursos dos especialistas quanto ao que é considerado como adequado nas práticas educativas adotadas pela família (Biasoli-Alves, 1997) também não contribui para atender à demanda dos pais, especialmente tendo em vista que nem sempre são sustentadas por pesquisas.

\section{Referências}

Alvarenga, P., \& Piccinini, C. A. (2001). Práticas educativas maternas e problemas de comportamento em pré-escolares. Psicologia: Reflexão e Crítica, 14(3), 449-460.

Alvarenga, P., \& Piccinini, C. (2003). Práticas educativas maternas e a interação entre mães e crianças com problemas de externalização. Aletheia, 17/18, 7-20.

Alvarenga, P., Piccinini, C. A., Frizzo, G. B., Lopes, R. C. S., \& Tudge, J. R. H. (2009). Estabilidade e mudanças nas práticas educativas de mães e pais dos 18 para os 24 meses de vida da criança. Revista Interação em Psicologia, 13(2), 253-262.

Bandura, A., \& Walters, R. H. (1959). Adolescent aggression. New York: The Ronald Press Company.

Bardin, L. (1977). Análise de conteúdo. (L. Reto \& A. Pinheiro, Trad.) São Paulo: Edições 70 / Livraria Martins Fontes.

Bentley, K. S., \& Fox, R. A. (1991). Mothers and fathers of young children: Comparison of parenting styles. Psychological Reports, 69, 320-322.

Belsky, J. (1984). The determinants of parenting: A process model. Child Development, 55, 83-96.

Biasoli-Alves, Z. M. (1997). Famílias brasileiras do século XX: Os valores e as práticas de educação da criança. Temas em Psicologia, 3, 33-49.

Biasoli-Alves, Z. M., \& Caldana, R. H. L. (1992). Práticas educativas: A participação da criança na determinação do seu dia-a-dia. Psicologia: Teoria e Pesquisa, 8(2), 231-242.

By Fu, N., \& Zheng, R. (2008). Influence of demographic factors on parenting locus of control. Chinese Journal of Clinical Psychology, 16(3), 289-291.

Bolsoni-Silva, A. T., \& Del Prette, A. (2002). O que os pais falam sobre suas habilidades sociais e de seus filhos? Argumento, 7, 71-86.
Braz, M. P., Dessen, M. A., \& Silva, N. L. P. (2005). Relações conjugais e parentais: Uma comparação entre famílias de classes sociais baixa e média. Psicologia: Reflexão e Crítica, 18(2), 151-161

Brook, J. Zheng, L., Whiteman, M., \& Brook, D. W. (2001). Aggression in toddlers: Associations with parenting and marital relations. Journal of Genetic Psychology, 162(2), 228-241.

Cia, F., Pereira, C. S., Del Prette, Z. A. P., \& Del Prette, A. (2006). Habilidades sociais parentais e o relacionamento entre pais e filhos. Psicologia em Estudo, 11(1), 73-81.

Dessen, M. A., \& Lewis, C. (1998). Como estudar a família e o pai? Paidéia, 8(14/15), 105-121.

Feinberg, M. E., \& Kan, M. L. (2008). Establishing family foundations: Intervention effects on coparenting, parent/infant well-being, and parent-child relations. Journal of Family Psychology, 22(2), 253-263

Frick, P. J., Christian, R. E., \& Wootton, J. N. (1999). Age trends in the association between parenting practices and conduct problems. Behavior Modification, 23(1), 106-128.

Grupo de Interação Social, Desenvolvimento e Psicopatologia - GIDEP-UFRGS/CNPq (1998a). Ficha de Contato Inicial. Instrumento Não-publicado. Instituto de Psicologia. Universidade Federal do Rio Grande do Sul.

Grupo de Interação Social, Desenvolvimento e Psicopatologia - GIDEP-UFRGS/CNPq (1998b). Entrevista de Dados Demográficos. Instrumento Não-publicado. Instituto de Psicologia. Universidade Federal do Rio Grande do Sul.

Grusec, J. E., \& Lytton, H. (1988). Socialization and the family. In J. E. Grusec \& H. Lytton (Eds.), Social development: History, theory and research (pp.161-210). New York: Springer-Verlag.

Hart, C. H., Ladd, G. W., \& Burleson, B. R. (1990). Children's expectations of the outcomes of social strategies: Relations with sociometric status and maternal disciplinary styles. Child Development, 61, 127-137.

Hart, C. H., DeWolfe, D. M., Wozniak, P., \& Burts, D. C. (1992). Maternal and paternal disciplinary styles: Relations with preschoolers' playground behavioral orientations and peer status. Child Development, 63, 879-892.

Hastings, P. D., Rubin, K. H., \& DeRose, L. (2005). Links among gender, inhibition, and parental socialization in the development of prosocial behavior. Merrill Palmer Quarterly, 51(4), 467-493.

Hoffman, M. L. (1975). Moral internalization, parental power, and the nature of parent-child interaction. Developmental Psychology, 11, 228-239.

Hoffman, M. L. (1994). Discipline and internalization. Developmental Psychology, 30, 26-28.

Hollingshead, A. B. (1975). Four factor index of social status. Unpublished manuscript, Department of Sociology. Yale University.

Javo, C., Ronning, J. A., Heyerdahl, S., \& Rudmin, F. W. (2004). Parenting correlates of child behavior problems in a multiethnic community sample of preschool children in northern Norway. European Child \& Adolescent Psychiatry, 13, 8-18.

Kuczynski, L., \& Grusec, J. E. (1997). Future directions for a theory of parental socialization. In J. E. Grusec \& L. Kuczynski (Eds.), Parenting and the internalization of values: A handbook of contemporary theory (pp. 399-414). New York: Wiley.

Lewis, C., \& Dessen, M. A. (1999). O pai no contexto familiar. Psicologia: Teoria e Pesquisa, 15, 9-16. 
Mills, R. S. L, Freeman, W. S., Clara, I. P., Elgar, F. J., Walling, B. R., \& Mak, L. (2007). Parent proneness to shame and the use of psychological control. Journal of Child and Family Studies, 16(3), 359-374

Mussen, P. (1992). Longitudinal study of the life span. In N. Eisenberg (Ed.), Contemporary topics in developmental psychology. New York: John Wiley \& Sons.

Mussen, P. H., Conger, J. J., Kagan, J., \& Huston, A. C. (1995). Socialização na família (M. L. G. L. Rosa, Trans.). In P. H. Mussen, J. J. Conger, J. Kagan \& A.C. Huston (Eds.), Desenvolvimento e personalidade da criança ( $3^{\mathrm{a}}$. ed., pp. 429-466). São Paulo: Harbra.

Newcombe, N. (1999). Socialização no cenário da família (C. Bucheveitz, Trans.). In N. Newcombe (Ed.), Desenvolvimento infantil: Abordagem de Mussen ( $8^{\text {a }}$. ed., pp. 336-363). Porto Alegre: Artes Médicas. (Original published in 1996)

Piccinini, C. A., \& Alvarenga, P. (2000). Entrevista sobre Práticas Educativas Parentais. Instrumento não-publicado. Instituto de Psicologia. Universidade Federal do Rio Grande do Sul.

Piccinini, C.A, Castro, E. K., Alvarenga, P., Vargas, S., \& Oliveira, V. Z. (2003). A doença crônica na infância e as práticas educativas maternas. Estudos de Psicologia, 8(1), 75-83.

Piccinini, C. A., Frizzo, G. B., Alvarenga, P., Lopes, R. C. S., \& Tudge, J. R. H. (2007). Práticas educativas maternas e paternas em crianças aos 18 meses de idade. Psicologia: Teoria e Pesquisa, 23(4), 369-378.

Piccinini, C. A., Maggi, A., \& Carro, J. (1993). Strategies used by mothers of German and Italian descent for regulating their children behavior. Trabalho apresentado na XXII Biennial Meeting, International Society for the Study of Behavior Development, Recife, Brasil.

Piccinini, C. A., Tudge, J. R. H., Lopes, R. C., \& Sperb, T. M. (1998). Projeto longitudinal de Porto Alegre: Da gravidez à escola. Projeto não-publicado, Curso de Pós-Graduação em Psicologia do Desenvolvimento, Universidade Federal do Rio Grande do Sul. Porto Alegre, RS.

Robson, C. (1995). Real word research: A resource for scientist and practiotioner-researchs. Oxford: U.K.: Blackwell.
Rouyer, V., Frascarolo, F., Zaouche-Gaudron, C., \& Lavanchy, C. (2007). Fathers of girls, fathers of boys: Influence of child's gender on fathers' experience of, engagement in, and representations of paternity. Swiss Journal of Psychology, 66(4), 225-233.

Silveira, L. M. O. B., Pacheco, J., Cruz, T., \& Schneider, A. A. (2005). Estratégias educativas desejáveis e indesejáveis: Uma comparação entre a percepção de pais e mães de adolescentes. Aletheia, 21, 31-42.

Tudge, J. R. H. (2008). The everyday lives of young children: Culture, class, and childrearing in diverse societies. New York: Cambridge University Press.

Tudge, J. R. H., \& Frizzo, G. F. (2002). Classificação baseada em Hollingshead do nível sócio-economico das famílias do estudo longitudinal de Porto Alegre: Da gestação à escola. Unpublished manuscript, Porto Alegre, RS.

Wagner, A. (2003). A família e a tarefa de educar: Algumas reflexões a respeito das famílias tradicionais frente a demandas modernas. In T. Féres-Carneiro (Ed.), Família e Casal: Arranjos e demandas contemporâneas (pp. 27-33). Rio de Janeiro: Editora Loyola.

Wagner, A., Predebon, J., Mosmann, C., \& Verza, F. (2005). Compartilhar tarefas? Papéis e funções de pai e mãe na família contemporânea. Psicologia: Teoria e Pesquisa, 21(2), 181-186.

Weber, L. N. D., Viezzer, A. P., \& Brandenburg, O. J. (2004). O uso de palmadas e surras como prática educativa. Estudos em psicologia, 9(2), 227-237.

Weber, L. N. D., Prado, P. M., Viezzer, A. P., \& Brandenburg, A. J. (2004). Identificação de estilos parentais: O ponto de vista dos pais e dos filhos. Psicologia: Reflexão e Crítica, 17(3), 323-331. 